\title{
Bioethanol Production From Pennisetum sp. Using Fed-Batch Simultaneous Saccharification and Co- Fermentation at High Solid Loadings and Its Life Cycle Analysis
}

Sonai Mohapatra ( $\square$ sonalimohapatra85@gmail.com )

College of Engineering and Technology, BBSR, India

Bikash Chandra Behera

School of Biological Sciences, NISER, BBSR

Achuyta Nanda Acharya

CET, BBSR

Hrudayanath thatoi

North Orissa University

Research

Keywords: Feeding strategy, Co-culture fermentation, Scale-up, Bioreactor, NMR

Posted Date: August 24th, 2020

DOI: https://doi.org/10.21203/rs.3.rs-58787/v1

License: (1) (1) This work is licensed under a Creative Commons Attribution 4.0 International License.

Read Full License 


\section{Abstract}

Considerable progress has been achieved for production of bioethanol from lignocellulosic biomass. However, increasing the substrate concentration has shown to decrease the ethanol productivity. In the present study, Saccharomyces cerevisiae and Pichia membreneferans were used for ethanol production from glucose and xylose sugars respectively in optimized conditions. Further, co-culture fermentations were conducted in three different strategies for $13 \mathrm{~g}$ of sugar ( $10 \mathrm{~g}$ of glucose and $3 \mathrm{~g}$ of xylose) and the best strategy was further used for ethanol production from ultrasonication assisted $\mathrm{NaOH}$ (UA-NaOH) pretreated and enzymatically saccharified in batch and fed-batch fermentation conditions. Further, fedbatch fermentation was used for separate hydrolysis and co-fermentation (SHCF) and simultaneous saccharification and co-fermentation (SSCF) in shake flask conditions. The highest ethanol production of 12.2 and $7.9(\mathrm{~g} / \mathrm{L})$ was observed for fed-batch SSCF denannath grass (DG) and Hybrid napier grass (HNG) (Palkonal MBW as the enzyme) biomass $(80 \mathrm{~g})$ respectively in shake flask conditions. However, increasing the biomass concentration to $270 \mathrm{~g}$ produced an ethanol concentration of 77.6 and $51.3(\mathrm{~g} / \mathrm{L})$ for DG and HNG respectively in fed-batch SSCF conditions in bioreactor. Nuclear magnetic resonance studies of the residual biomass of both DG and HNG revealed presence of lower carbohydrate content, demonstrating the efficiency of the fermentation strategy. Further Life cycle Analysis (LCA) was also conducted to analyzed the effect of the ethanol on different environmental conditions

The substrate feeding strategy and the saccharifying enzymes play a major role for efficient bioethanol production with higher substrate loadings. Presence of lower carbohydrates and some lignin moieties demonstrating the efficiency of the SSCF strategy for maximum conversion of carbohydrates. Thus fed batch SSCF process can be considered as a promising technique for biorefinery based bioethanol production from Pennisetum sp. in the future.

\section{Introduction}

The rise in demand of fossil fuels due to the increase in population has led to emergence of exploring renewable alternatives such as biofuel which has the potential to meet the future energy demands (Kalyani et al. 2017). The annual production of biofuels such as bioethanol and biodiesel are approximately 89 billion litres and 24 billion litres respectively in the year 2015 with continuous increase in its production and demand in the present years. Though sugar and starch containing crops (1st generation feedstocks) have been the main source of bioethanol in the US and Brazil, their role as food crops limits their extensive use for bioethanol production in the future. On the other hand lignocellulosic biomass (2nd generation feedstocks) in the form of agricultural and woody residues or energy crops which do not interfere with food applications presents a near-term solution to supporting energy demands (Nguyen et al. 2017).

Lignocellulosic biomass is composed of celluloses, hemicelluloses and lignin which forms a network like structure and offers rigidity and recalcitrance nature to the cell wall. Pretreatment is an essential step for overcoming the recalcitrance nature of cell wall which eliminates most of the lignins with simultaneous 
breakage of lignin-carbohydrate linkages. This eventually leads to easy accessibility of the enzymes to the cellulose and hemicellulose (Mohapatra et al. 2017). However, the efficacy of the pretreatment is greatly dependent on the type of pretreatment and biomass used. Subsequently, in the next step the enzymes saccharify the cellulose and hemicelluloses to glucans and xylans, which can further be fermented to ethanol by efficient fermentative organisms. Grasses which are generally referred as energy crops consist of lower concentrations of lignin although the linkage patterns for lignin-carbohydrate complexes are mostly similar as that of other lignocellulosic biomass (Xiros et al. 2014). Hence mild pretreatments like alkaline or alkaline pretreatments combined with ultrasonication have been observed to showcase higher delignification rates in grass biomass (Mohapatra et al. 2018). Nevertheless, the further steps of saccharification and fermentation can either be conducted separately (separate hydrolysis and fermentation) or simultaneously (simultaneous saccharification and fermentation) depending on the type of microorganism used for fermentation.

Appropriate selection of microorganism for the conversion of monomeric sugars to ethanol from biomass is the key point for all fermentation processes. The literature survey reveals many fermentative organisms such as bacteria, yeast and fungus that are efficient in conversion of these monosaccharides into ethanol. However, alike enzymes it is important to choose the microorganisms involved in the fermentation of lignocellulosic sugars into bioethanol (Singh et al. 2017) as the selection of the microorganisms is dependent on the substrate used. For example, Zymomonas mobilis, a gram negative bacterium has gained the attention of the scientific community as an efficient microorganism for conversion of hexose sugar to ethanol (Gu et al. 2015). However, owing to its restricted substrate accessibility, yeasts like Saccharomyces cerevisiae have been more preferred over bacterial strains. Several strains of S.cerevisiae have exhibited remarkable fermentation capabilities for sugary and starchy substrates which are rich in hexose sugar (Westman et al. 2017). But, lignocellulosic biomasses like grass feedstocks consist of pentose sugars, though in lower proportions, along with the hexose sugars. Hence, for utilization of these pentose sugars either the hexose fermenting strains have to be genetically modified or a co-culture system has to be selected in which both hexose and pentose fermenting yeasts can convert the sugars into ethanol. The later process appears to be more feasible from economical prospective of lignocellulosic bioethanol production as genetically modifying an organism is time consuming and the final outputs may or may not be encouraging. The majority of pentose fermenting yeasts belongs to Pichia membreneferans. which in the absence of glucose can solely use xylans or arabinoxylans as their carbon source. However, in the presence of glucose these microorganisms exhibit better preference towards the same.

To obtain maximum utilisation of the sugars those are produced during saccharification of grass biomass, the co-fermentation strategy need to be optimised. The first measure that has to be considered is the feed system which generally consists of batch or a fed batch strategy. Generally, batch systems involve the addition of all the feed (substrate), enzymes and microorganisms at a time whereas in feedbatch the substrate is fed in the reaction mixture at regular intervals with the enzymes and microorganisms given in the beginning of the process (Gao et al. 2014). Further, the feed system has to be integrated with the saccharification system i.e. a separate hydrolysis and co-fermentation (SHCF) or 
simultaneous saccharification and co-fermentation (SSCF). Compared to SHCF, SSCF have been observed to potentially decrease the capital and operational costs with simultaneous decrease of endproduct inhibition of enzymes and reduced contamination (Paulova et al. 2015; Amillastre et al. 2012). Different parameters affect the efficiency of fermentation processes, however temperature has a vital effect as compared to others. Maintaining the appropriate temperature for culture conditions, plays an important role in SSCF, as it has to be compromised between high temperatures at about $50{ }^{\circ} \mathrm{C}$ that are optimal for cellulolytic or xylanolytic enzymes and lower temperatures of $30-35{ }^{\circ} \mathrm{C}$ that are preferred by both hexose and pentose fermenting organisms. The fed-batch SSCF in contrast to fed-batch SHCF offers advantage in processes with high solid loadings due to less accumulation of glucose, wherein the sugars are continuously removed by fermentation (Olofsson et al. 2010).

With these insights the experiments in the present investigation were designed with the following objectives; a) screening and optimisation of single and co-fermentation conditions in pure hexose and pentose sugars, b) selection of the type of fermentation process for pretreated and saccharified DG and HNG biomass in shake flask conditions (the pretreatment and saccharification conditions were previously optimised by the authors) and c) scale-up of the best type of fermentation process in bioreactor. The quantification of ethanol that was produced in the above process was conducted using gaschromatography while the structural variations in the fermented biomass were observed using nuclear magnetic resonance spectroscopy (NMR).

\section{Results And Discussions}

\section{Microorganisms for ethanol production}

Saccharomyces cerevisae and Pichia sp. were selected for mono and co-culture ethanol production from grass biomass on the basis of optimisation results (data not shown). For the $S$. cerevisiae mono culture fermentation the optimum ethanol production of $3.7 \mathrm{~g} / \mathrm{L}$ from was obtained at $72 \mathrm{~h}$ of incubation at 30 ${ }^{\circ} \mathrm{C}$ with $10 \mathrm{~g} / \mathrm{L}$ of glucose as the substrate. For Pichia sp. the aforementioned parameters exhibited the highest ethanol production of $3.1 \mathrm{~g} / \mathrm{L}$ from $10 \mathrm{~g} / \mathrm{L}$ of xylose as the sole carbon source. The parameters optimized in the mono-culture fermentation i.e. incubation time $72 \mathrm{~h}$, temperature- $30^{\circ} \mathrm{C}$, shaking velocity$120 \mathrm{rpm}$, glucose: xylose concentration- $10: 3(\mathrm{~g} / \mathrm{L})$ and inoculum volume of $8 \mathrm{~mL}(6: 2)$ were further used to screen co-culture fermentation conditions using $S$.cerevisiae and Pichia sp. Three conditions were considered (data not shown), among which the third condition (Condition III) wherein $13 \mathrm{~g} / \mathrm{L}$ of substrate was first fermented by $S$. cerevisiae for $48 \mathrm{~h}$, followed by centrifugation at $7000 \mathrm{rpm}$ for separation of supernatant, followed by Pichia sp. for $24 \mathrm{~h}$. The total sugar utilized in this fermentation process was 6.8 $\mathrm{g} / \mathrm{L}$ and the final ethanol concentration was $3.0 \mathrm{~g} / \mathrm{L}$. The results from the co-culture experiments indicated that condition III was the most preferred condition for fermentation. However, although the results of co-culture fermentation were lower as compared to the monoculture system, the co-culture systems are preferred for various reasons. Co-culture systems for bioethanol production from lignocellulosic biomass are evidenced to be more advantageous as compared to single cultures mainly 
because of the synergistic action of the metabolic pathways of the involved strains that helps in combating the stress and enhancing the ethanol productivity (Bader et al. 2010).

\section{Pretreatment and Saccharification}

The optimum pretreatment conditions of $60 \mathrm{~W}$ (ultrasonication watt), $40{ }^{\circ} \mathrm{C}$ for 40 minutes for Dennanath grass (DG) and $70 \mathrm{~W}, 40{ }^{\circ} \mathrm{C}$ with an incubation of 50 mins for Hybrid napier grass (HNG) revealed maximum lignin removal of $89.3 \%$ and $86.7 \%$ for $D G$ and $H N G$ respectively. In the same parametric conditions, the reducing sugars for DG and HNG were observed to be $227.2 \pm 0.2 \mathrm{mg} / \mathrm{g}$ and $242.8 \pm 0.6$ $\mathrm{mg} / \mathrm{g}$ of raw biomass respectively (Mohapatra et al., 2017). Palkonol MBW enzyme showed enhanced enzymatic hydrolysis with maximum total reducing sugar (TRS) release of $662.0 \pm 0.5 \mathrm{mg} / \mathrm{g}$ and $433.4 \pm$ $0.3 \mathrm{mg} / \mathrm{g}$ in DG and HNG variety respectively. The mixture of IC + xylanase revealed a maximum TRS of $421.3 \pm 0.3 \mathrm{mg} / \mathrm{g}$ in DG samples while for HNG reduced TRS of $483.8 \pm 0.5 \mathrm{mg} / \mathrm{g}$ was observed (Mohapatra et al., 2018). While the optimized parameters for saccharification conditions were maintained for separate hydrolysis and co-fermentation, the parameters such as temperature and incubation time were compromised for simultaneous saccharification and co-fermentation.

\section{Batch and fed-batch fermentation of DG and HNG using co-culture of $S$. cerevisiae and Pichia sp.}

Further co-culture system has to be integrated with the appropriate input of feed process. Therefore two feed strategies i.e. batch and fed-batch, were experimented for ethanol production from two grass verities DG and HNG with the co-culture of S. cereviciae and Pichia sp. Batch experiments were conducted using $20 \mathrm{~g} / \mathrm{L}$ of UA-NaOH pretreated DG and HNG biomass as shown in Table SII(a). For both DG and HNG the substrate concentration of $20 \mathrm{~g} / \mathrm{L}$ and enzyme (Palkonal MBW) were taken in $2000 \mathrm{~mL}$ flask separately. The flasks were incubated for $48 \mathrm{~h}$ for saccharification and the glucose to xylose ratio was determined to be 10:3 and 6.5:2 (g) for DG and HNG respectively. The organisms (S. cerevisiae and Pichia sp.) were inoculated according to condition III of the screening experiments mentioned in the previous section. In case of DG, the total sugar concentration of $13 \mathrm{~g} / \mathrm{L}$ resulted in $1.9 \mathrm{~g} / \mathrm{L}$ of ethanol concentration. Similarly, in case of HNG a total of $1.5 \mathrm{~g} / \mathrm{L}$ of ethanol was produced from $8.5 \mathrm{~g} / \mathrm{L}$ of sugar.

Fed-batch experiments were conducted using $20 \mathrm{~g} / \mathrm{L}$ of UA-NaOH pretreated and saccharified DG and HNG. The feed for fed-batch fermentation for both DG and HNG biomass was given for the total time of 8 $\mathrm{h}$. The feed was increased rapidly from 2.2 to $8.2(\mathrm{~g} / \mathrm{L})$ in the first $5 \mathrm{~h}$ after which the last feed was lowered to $5 \mathrm{~g}$. Using this strategy the total ethanol concentration of $2.9 \mathrm{~g} / \mathrm{L}$ was observed from $6.4 \mathrm{~g} / \mathrm{L}$ of DG and $2.1 \mathrm{~g} / \mathrm{L}$ from $5.2 \mathrm{~g} / \mathrm{L}$ of HNG. The results from the co-culture batch and fed-batch experiments revealed that co-culture system integrated with fed-batch mode produced higher titers of bioethanol as compared to co-culture system integrated with batch mode. Batch mode fermentations though are simple and easier to control but exhibit a lot of bottlenecks. One example is the suppression of xylose fermentation in the presence of glucose specifically in the initial stages of fermentation (Grootjen et al., 1991). Further, most of the experiments conducted till date is either carried in co-culture batch or continuous fermentation mode. More recently, studies have been conducted using co-culture feed-batch mode for bioethanol production from wheat straw and have been observed to produce higher ethanol 
yields (Nielsen et al., 2017). Co-culture fed-batch mode has the potential to affect culture growth and avoid overflow metabolism due to the feeding of a growth-limiting nutrient substrate. Furthermore, fedbatch mode of fermentation can also help in solving the problem that generally arises when the rising inhibitor concentrations adversely affects the ethanol production for pentose-fermenting yeasts by maintaining an optimum dilution rate (Cardona et al., 2007).

\section{Fed-batch SHCF and SSCF processes for UA-NaOH pretreated DG and HNG biomass}

Apart from the mode of fermentation, the process opted i.e. separate hydrolysis and co-fermentation (SHCF) or simultaneous saccharification and co-fermentation (SSCF) integrated with fed-batch mode is an important aspect for bioethanol production from lignocellulosic biomass (Koppram et al. 2013). UA$\mathrm{NaOH}$ pretreated DG and HNG were subjected to SHCF and SSCF processes in fed-batch technique separately. The processes were conducted separately for combination of IC+XyI (Isolated cellulase + commercial xylanase) and commercial enzyme (Palkonal MBW). The substrate loadings for DG and HNG were taken as $20,40,60$ and $80(\mathrm{~g})$. The supply of feed rate ( $\mathrm{g}$ of substrate/ time interval) for both SHCF and SSCF was fixed to $8 \mathrm{~h}$. For SHCF process the pretreated DG and HNG were first enzymatically saccharified in the optimized conditions and then subjected to fed-batch co-culture fermentation. For SSCF experiments the initial feed was kept $20 \%$ of the total feed and the total enzyme concentration was given with the initial feed concentration and incubated for $24 \mathrm{~h}$ at temperature of $50^{\circ} \mathrm{C}$. After $24 \mathrm{~h}$ the temperature was lowered to $35^{\circ} \mathrm{C}$ and the organisms (S.cerevisiae and P.membranifaciens) were inoculated according to condition III. The efficiency of the SHCF and SSCF processes were evaluated on the basis of ethanol production and the best process was further chosen to conduct reactor scale fermentation using substrate concentration of $270 \mathrm{~g}$ of DG and HNG biomass.

\section{Fed-batch SHCF of UA-NaOH pretreated DG and HNG using Palkonal MBW and IC+Xyl enzymes and co- culture of S.cerevisiae and P.membranifaciens}

The glucose and xylose concentrations of DG and HNG before and after fermentation, the total sugar utilized and the ethanol concentration during fed-batch SHCF process using Palkonal MBW is as given in Fig. 1(I). For DG, ethanol concentration of $2.9 \mathrm{~g} / \mathrm{L}$ was obtained from $20 \mathrm{~g}$ of biomass which consisted 10 $\mathrm{g}$ of glucose and $3 \mathrm{~g}$ of xylose sugars. The total sugar utilized in the fed-batch SHCF process was $6.4 \mathrm{~g}$. When the biomass concentration was increased to 40,60 and $80(\mathrm{~g})$ the increase in ethanol concentration was observed to be only $18.3,29.2$ and 34 (\%) respectively. The total sugar utilized for 40 , 60 and 80 (g) of DG were 10.4, 12.4 and 15.8 (g) respectively. In case of HNG, fed-batch SHCF of $20 \mathrm{~g}$ of biomass resulted in $2.1 \mathrm{~g} / \mathrm{L}$ of ethanol. Increase in biomass concentration to 40,60 and 80 (g) resulted in an increase in ethanol concentration of 19.6, 19.2 and 33.3 (\%) respectively as compared to $20 \mathrm{~g}$ of biomass concentration. However, ethanol concentration was observed to slightly decrease for $60 \mathrm{~g}$ of biomass as compared to $40 \mathrm{~g}$ of HNG using fed-batch SHCF. The results illustrated that when biomass concentration was increased, ethanol production from DG was higher as compared to HNG in fed-batch SHCF process using Palkonal MBW. 
Fig. 1(II) depicts the glucose and xylose concentrations of DG and HNG before and after fermentation, the total sugar utilized and the ethanol concentration during fed-batch SHCF process using IC+XyI enzyme. In DG, $20(\mathrm{~g})$ of UA-NaOH pretreated and saccharified biomass with glucose content of $5 \mathrm{~g}$ and xylose content of $4.4 \mathrm{~g}$ was fermented using fed-batch SHCF process to produce an ethanol concentration of 2.1 $\mathrm{g} / \mathrm{L}$. The total sugar utilized in the co-culture fermentation process was $5.3 \mathrm{~g}$. Further, increasing the substrate concentration to 40,60 and 80 (g) resulted in increased ethanol concentration of 20.7, 17.6 and $40(\%)$ respectively as compared to $20 \mathrm{~g}$ of biomass of DG. Nevertheless, the increase in substrate concentration from 40 to $60 \mathrm{(g}$ ) led to a reduced ethanol concentration in DG. In case of UA-NaOH pretreated and saccharified HNG, the glucose and xylose concentration were found to be 6 and $3.6(\mathrm{~g})$ respectively for $20 \mathrm{~g}$ of biomass. Increasing the substrate concentration to 40,60 and 80 (g) resulted in an increase of $29.8,34.4$ and 44.4 (\%) ethanol concentrations respectively. The results indicated that the combination of isolated cellulase and commercial xylanase was more beneficial for HNG as compared to DG in fed-batch SHCF process.

\section{Fed-batch SSCF of UA-NaOH pretreated DG and HNG using Palkonal MBW and IC+Xyl enzymes and co- culture of S.cerevisiae and P.membranifaciens}

The first set of fed-batch SSCF experiments were conducted for UA-NaOH pretreated DG and HNG biomass using Palkonal MBW enzyme is as shown in Fig. 2(I). Since, the enzymatic saccharification and fermentation occurs simultaneously the glucose and xylose concentrations in the fermented broth of DG and HNG after the completion of partial enzymatic hydrolysis $(24 \mathrm{~h})$ and after fermentation process was observed. For DG, ethanol concentration of $3.6 \mathrm{~g} / \mathrm{L}$ was obtained from $20 \mathrm{~g}$ of biomass. The residual sugar in the fermentation medium after the fed-batch SHCF process was $4.8 \mathrm{~g}$. When the biomass concentration was increased to 40,60 and $80(\mathrm{~g})$ the increase in ethanol concentration was $26.5,41.4$ and $54.4(\%)$ respectively. The residual sugar for 40, 60 and 80 (g) of DG were 15, 19.8 and $26.3(\mathrm{~g})$ respectively. In case of HNG, fed-batch SHCF of $20 \mathrm{~g}$ of biomass resulted in $2.2 \mathrm{~g} / \mathrm{L}$ of ethanol. Increase in biomass concentration to 40,60 and $80(\mathrm{~g})$ resulted in an increase in ethanol concentration of 35.2, 45.0 and 56.4 (\%) respectively as compared to $20 \mathrm{~g}$ of HNG biomass concentration. The residual sugar for 40, 60 and $80(\mathrm{~g})$ of HNG were 10.4, 13.9 and $16.6(\mathrm{~g})$ respectively. In fed-batch SSCF process using Palkonal MBW as the saccharifing enzyme, increase in biomass concentration led to higher ethanol production from HNG as compared to DG.

The second set of fed-batch SSCF experiments were conducted for UA-NaOH pretreated DG and HNG biomass using IC+Xyl enzyme is as shown in Fig. 2(II).Similar to the first set of fed-batch SSCF experiments, only the residual sugar (glucose and xylose) left in the fermented broth of DG and HNG was calculated. In DG, 20 (g) of UA-NaOH pretreated biomass produced an ethanol concentration of $2.9 \mathrm{~g} / \mathrm{L}$. The residual sugar concentration in the co-culture fermented DG broth was observed to be $3.9 \mathrm{~g}$. Further, increasing the substrate concentration to 40,60 and 80 (g) resulted in increased ethanol concentration of $27.5,30.1$ and 45.7 (\%) respectively as compared to $20 \mathrm{~g}$ of biomass of DG. In case of UA-NaOH pretreated HNG, the residual sugar and ethanol concentration was found to be $3.4 \mathrm{~g}$ and $2.9 \mathrm{~g} / \mathrm{L}$ respectively for $20 \mathrm{~g}$ of biomass. Increasing the substrate concentration to 40,60 and 80 (g) resulted in 
an increase of 2.3, 30.0 and 43.2 (\%) ethanol concentrations respectively as compared to $20 \mathrm{~g}$ of HNG biomass. The results indicated that the combination of isolated cellulase and commercial xylanase was more beneficial for DG as compared to HNG in fed-batch SSCF process. Literature studies state that fedbatch SSCF process can prove to be efficient process in reduction of inhibitors which eventually interfere in the enzyme-substrate reaction (Almeida et al. 2007). Further, fed-batch SSCF also offers the advantage of using higher substrate loadings due to the ease of mixing the substrate which ultimately produces high ethanol concentrations (Zhang et al. 2010). Consequently, it also offers a possibility to maintain glucose at low levels allowing efficient co-fermentation of glucose and xylose (Ohgren et al. 2010).

\section{Fed-batch SSCF of UA-NaOH pretreated DG and HNG using Palkonal MBW and IC+Xyl enzymes and co- culture of S.cerevisiae and P.membranifaciens in bioreactor}

Reactor scale experiments were conducted for UA-NaOH pretreated DG and HNG biomass using Palkonal MBW and IC+Xyl enzymes separately in fed-batch SSCF process as given in Table S III. Since, the fedbatch SSCF experiments resulted in higher ethanol production both in DG and HNG as compared to fedbatch SHCF, reactor scale experiments were further conducted using the former process. A total of $270 \mathrm{~g}$ of $\mathrm{UA}-\mathrm{NaOH}$ pretreated biomass each for DG and $\mathrm{HNG}$ were used in fed-batch SSCF experiments and the glucose and xylose concentrations in the fermented broth of DG and HNG after the completion of partial enzymatic hydrolysis $(24 \mathrm{~h})$ and after fermentation process was observed.

For UA-NaOH pretreated DG [DG (A) in Table S III] the glucose and xylose concentration after $24 \mathrm{~h}$ of partial hydrolysis (Palkonal MBW) were 72.1 and 19.3 (g) respectively. In the end of co-culture fermentation of $96 \mathrm{~h}$ ( $24 \mathrm{~h}$ for partial hydrolysis and $72 \mathrm{~h}$ for co-culture fermentation) the residual glucose and xylose concentrations were 1.8 and $0.2(\mathrm{~g})$ with an ethanol concentration of $77.6 \mathrm{~g} / \mathrm{L}$ from $270 \mathrm{~g}$ of UA-NaOH pretreated DG. For the second enzyme (IC+Xyl), [DG (B) in Table S III] the glucose and xylose concentrations after $24 \mathrm{~h}$ of partial hydrolysis of $\mathrm{UA}-\mathrm{NaOH}$ pretreated DG were 36.3 and $20.7 \mathrm{~g}$ ) respectively. The residual glucose and xylose concentrations after the fermentation cycle were 1.5 and $0.4 \mathrm{~g}$ ) respectively with a total ethanol concentration of $51.3 \mathrm{~g} / \mathrm{L}$ from $270 \mathrm{~g}$ of UA-NaOH pretreated DG. The ethanol concentrations for DG saccharified with commercial enzyme (Palkonal MBW) were much higher as compared to the mixture of isolated cellulase and xylanase enzymes.

For UA-NaOH pretreated HNG [HNG (A) in Table S III] the glucose and xylose concentration after $24 \mathrm{~h}$ of partial hydrolysis (Palkonal MBW) were 33.4 and 15.3 (g) respectively. In the end of co-culture fermentation of $96 \mathrm{~h}$ ( $24 \mathrm{~h}$ for partial hydrolysis and $72 \mathrm{~h}$ for co-culture fermentation) the residual glucose and xylose concentrations were 1.5 and $0.7(\mathrm{~g})$ with an ethanol concentration of $49.6 \mathrm{~g} / \mathrm{L}$ from $270 \mathrm{~g}$ of UA-NaOH pretreated DG. For the second enzyme (IC+Xyl), [HNG (B) in Table S III] the glucose and xylose concentrations after $24 \mathrm{~h}$ of partial hydrolysis of $\mathrm{UA-NaOH}$ pretreated HNG were 46.9 and 19.4 (g) respectively. The residual glucose and xylose concentrations after the fermentation cycle were 1.2 and 0.3 (g) respectively with a total ethanol concentration of $54.9 \mathrm{~g} / \mathrm{L}$ from $270 \mathrm{~g}$ of UA-NaOH pretreated HNG. The ethanol concentrations for HNG saccharified with mixture of isolated cellulase and xylanase enzymes were slightly higher as compared to the commercial enzyme (Palkonal MBW). 


\section{NMR analysis}

Solid state NMR of the residual solid fractions of the fed-batch SSCF DG and HNG biomass in bioreactor was conducted. The residual solid biomass that is left over after the extraction of ethanol primarily consists of lignin and unconverted sugars. The purpose of conducting NMR analysis in the present study was to observe the efficacy of the process for optimum utilization of carbohydrates during the fed batch simultaneous saccharification and fermentation process. The chemical shift assignments are based on the comparison of the ${ }^{13} \mathrm{C}$ NMR spectra from the switch grass and sugarcane bagasse (Watkins et al. 2015). The explanation for the chemical shifts that are depicted in Fig. S (I) are presented in three parts i.e. lignin, hemicellulose and cellulose in this section.

Lignin- Lignin related peaks were observed in all the samples of DG and HNG. While the peaks at 57.4 and $56.1 \mathrm{rpm}$ were observed for Palkonal MBW saccharified and simultaneously co-fermented DG and HNG respectively, peaks at 56.3 and $57.1 \mathrm{rpm}$ were observed for IC+ Xyl saccharified and simultaneously co-fermented DG and HNG respectively. The peaks belonged to the aliphatic lignin group which are related to oxygenated $\mathrm{Ca}, \mathrm{C} \beta$, and $\mathrm{C} Y$ carbons of the phenyl propane in lignin.

Hemicellulose: The peaks related to hemicellulose were observed in 73.0 and $76.0 \mathrm{rpm}$ for Palkonal MBW saccharified and simultaneously co-fermented DG and 73.0 and 75.0 ppm for Palkonal MBW saccharified and simultaneously co-fermented HNG. For IC+ Xyl saccharified and simultaneously co-fermented DG and HNG peaks at 74.7 and $75.0 \mathrm{ppm}$ were observed respectively. These peaks are attributed to xylose units of hemicellulose and to carbon units of lignin.

Cellulose: No cellulose related peaks were observed for Palkonal MBW saccharified and simultaneously co-fermented DG. However Palkonal MBW saccharified and simultaneously co-fermented HNG exhibited only one peak at $84.7 \mathrm{ppm}$ corresponding to $\mathrm{C} 4$ carbon of amorphous cellulose. Further peaks at 83.0, 84.0, 85.9 and 105.0 ppm were observed for IC+ Xyl saccharified and simultaneously co-fermented DG while for HNG only a single peak at 84.7 was observed. Peaks corresponding to 84.2-89.0 are attributed to $\mathrm{C} 4$ carbon of crystalline and non-crystalline cellulose regions. However, the same region is also contributed by signals from lignin and hemicellulose, but the latter one not contributing significantly in the same spectral regions.

It was evident from the results that, fed-batch SSCF DG biomass predominantly consisted more of lignin and hemicellulose while fed-batch SSCF HNG exhibited more unutilised cellulose peaks with few lignin peaks. Similar results as that for fed-batch SSCF DG biomass was obtained by Sannigrahi and Ragauskas (2011) using miscanthus and switchgrass residues that were fermented for bioethanol production. Although most of the dried solid stream $(\sim 40 \%)$ in bioethanol plants, after ethanol production is diverted to meet the thermal requirements of pretreatment and ethanol distillation (Watkins et al., 2015) still $\sim 60 \%$ of these residues are left out unutilized. Hence, characterization of residual biomass can be helpful for production of value added products and consequently better techno-economic evaluations for industrial bioethanol production.. 


\section{LCA Analysis}

The LCA analysis was conducted for the fermented DG and HNG samples that were obtained 828 in fedbatch SSCF experiments in the bioreactor Fig. 3 (I). The results show that a total 829 ethanol yield of 26 $\%$ is obtained for DG biomass during the fed batch SSCF experiments in 830 bioreactor. Similar results can be obtained when the production is scaled up, i.e, $192 \mathrm{~kg}$ of 831 fermentation substrate would produce around $50 \mathrm{~kg}$ of ethanol. For the same, a total of $385832 \mathrm{~kg}$ of raw biomass would be required. In case of HNG, a $20 \%$ ethanol yield was observed. 833 From general mass balance, $250 \mathrm{~kg}$ of alkali pretreated and sonicated biomass sample was 834 able to produce $50 \mathrm{~kg}$ of ethanol. For the same, a total raw biomass of $722 \mathrm{~kg}$ would be 835 required. Since HNG is a hybrid grass, its production process would have its own 836 environmental impact but since the raw material was directly purchased, the associated 837 impacts have been kept out of the scope of the study. As is clearly observed, for the same 838 amount of production of ethanol, we need more HNG than DG. Since the associated impacts 839 consider mostly the consumption of electricity and thermal energy (if any), obviously the 840 impacts associated with the production of ethanol from HNG would be more than that of DG.

The environmental analysis was carried out for the production of $50 \mathrm{~kg}$ of ethanol from the $842 \mathrm{DG}$ and HNG biomass as given in Fig. 3(II). The method used to calculate the impacts 843 associated was ReCiPe calculation method. It is an end-point calculation method which 844 translates emissions and resource extractions into a limited number of environmental impact 845 scores by means of so-called characterisation factors. It expresses the aggregation of the midpoint indicators in terms of impacts on three main categories namely: effect on human 847 health (human toxicity), biodiversity (global warming potential/climate change) and resource 848 scarcity (water depletion) (Bai et al., 2010). The production process that used DG as the raw 849 biomass showed a total GWP of 261.76 (kg CO2 equivalents), while that from HNG 850 showed 765.65 (kg CO2 equivalents). This was mainly due to the increased electricity (and 851 thermal energy, if any) consumed for the treatment of a higher volume of biomass. Similarly, 852 for ethanol production from DG, the freshwater ecotoxicity was calculated to be 0.015 (kg 8531,4 dichlorobenzene equivalents) while the same from HNG was found to be 0.074 ( $\mathrm{kg} \mathrm{1,4-} 854$ dichlorobenzene equivalents). Again for the production of ethanol from DG, the water 855 depletion was found to be $2.75 \mathrm{~m} 3$ while that from HNG was determined to be $8.56 \mathrm{~m} 3$.Since 856 the production from both the substrates used similar experimental arrangement, the results 857 followed the same pattern in terms of the impacts. The findings of our study show a common 858 trend in terms of impacts associated with individual unit processes. It was found that, for both 859 the substrates, ball milling and alkali pre-treatment constituted the major fraction of the total 860 impacts for every impact category.

It is evident from the studies that, the production of ethanol from DG had a higher yield as 862 well as lower environmental impact than HNG. The impacts associated with ethanol 863 production from HNG would have been higher had its production process been considered as 864 it is a hybrid variety. But this was excluded from the scope of the study as the raw material 865 was directly purchased from vendor. The common trend followed by the individual unit 866 processes in terms of environmental impacts is because of the fact that the unit processes 867 involved use primarily electricity and/or thermal energy as 
inputs. Hence the process which 868 consumes more electricity and/or thermal energy contributes more to the overall impacts of 869 the process as a whole.

\section{Conclusion}

This study highlighted that co-culture fed batch fermentation strategy showed improved ethanol production for both the Pennisetum sp. as compared to co-culture batch fermentations. Further when fed batch strategy was used for simultaneous saccharification and co-fermentation (SSCF) in bioreactor, higher ethanol titers of 77.6 and $51.3(\mathrm{~g} / \mathrm{L})$ from $270 \mathrm{~g}$ of DG and HNG biomass were obtained respectively. It is evident from the present study that the substrate feeding strategy and the saccharifying enzymes play a major role for efficient bioethanol production with higher substrate loadings. Furthermore, NMR studies revealed presence of lower carbohydrates and some lignin moieties demonstrating the efficiency of the SSCF strategy for maximum conversion of carbohydrates. Thus, the current work confirms that using of fed batch SSCF process can be considered as a promising technique for biorefinery based bioethanol production from Pennisetum sp. in the future.

\section{Material And Methods}

\section{Microorganism}

The ethanol producing strains of Saccharomyces cerevisiae and Pichia membreneferans. were previously isolated and characterized in Dept. of Biotechnology, CET (Dash et al., 2014). The organisms were grown at $30{ }^{\circ} \mathrm{C}$ and maintained on an agar medium containing yeast extract $(10 \mathrm{~g} / \mathrm{l})$, peptone $(20 \mathrm{~g} / \mathrm{l})$, dextrose $(20 \mathrm{~g} / \mathrm{l})$ and agar $(1.5 \mathrm{~g} / \mathrm{l})$ in sterile distilled water. The $\mathrm{pH}$ of the medium was adjusted to 6.0 using $1 \mathrm{~N}$ $\mathrm{NaOH}$ solution. The cultures were maintained at $4{ }^{\circ} \mathrm{C}$ and sub-cultured freshly for each of the experiments.

\section{Pretreatment and saccharification of DG and HNG biomass}

Ultrasonication assisted $\mathrm{NaOH}(\mathrm{UA}-\mathrm{NaOH})$ pretreatment was conducted in the conditions as previously described in Mohapatra et al., 2019. The pretreated DG and HNG biomass were further saccharified at optimized parameters using two different set of enzymes. The $1^{\text {st }}$ set of enzymes consisted of Palkonal MBW (a mixture of cellulase- 12000 Maps cellulase unit (MCU) / $\mathrm{mL}$ and hemicellulose- $5000 \mathrm{MHCU} / \mathrm{mL}$ ) (Mohapatra et al, 2019) while the second set of enzymes consisted of Isolated cellulase (IC) + commercial xylanase (Xyl) [enzyme activity of the IC was $1.35 \mathrm{U} / \mathrm{mL}$ and $8450 \mathrm{U} / \mathrm{ml}$ for Xyl enzyme] (Mohapatra et al., 2018). Briefly, the optimised parameters for saccharification using the $1^{\text {st }}$ set of enzymes (Palkonal MBW) were temperature-50 ${ }^{\circ} \mathrm{C}, \mathrm{pH}-5.25$, enzyme concentration- $250 \mu$ l and incubation time of $30 \mathrm{~h}$ for $\mathrm{DG}$ and temperature $45^{\circ} \mathrm{C}, \mathrm{pH}-5$, enzyme concentration-200 $\mu \mathrm{l}$ and incubation time of 40 $\mathrm{h}$ for HNG. Similarly, for the second set of enzymes (IC+Xyl) optimum conditions of temperature- $35{ }^{\circ} \mathrm{C}$, $6.25 \mathrm{pH}$, incubation time $-48 \mathrm{~h}$ and enzyme ratio of $2.5 \mathrm{~mL}: 200 \mu \mathrm{l} / \mathrm{g}$ was kept for DG while temperature$35^{\circ} \mathrm{C}, 7.0 \mathrm{pH}$, incubation time $-30 \mathrm{~h}$ and enzyme ratio of $1.5 \mathrm{~mL}: 200 \mu \mathrm{l} / \mathrm{g}$ was maintained for HNG. While 
the optimised parameters for saccharification conditions were maintained for separate hydrolysis and cofermentation, the parameters such as temperature and incubation time were slightly compromised for simultaneous saccharification and co-fermentation.

\section{Fermentation process for ethanol production from pretreated and saccharified DG and HNG biomass}

The optimized [Denannath grass (DG) and Hybrid napier grass (HNG)] and enzyme saccharified grass biomass were used as fermentation substrates in the experiments. Commercial enzyme Palkonal MBW (Maps Pvt. Ltd) and mixture of Isolated cellulase + xylanase (IC+Xyl) were used in two separate sets for saccharification and fermentation of DG and HNG. The best condition obtained from the screening of coculture fermentation i.e. Condition III was used for all the SHCF and SSCF experiments of DG and HNG biomass. Control experiments were conducted for batch and fed-batch fermentation systems in separate hydrolysis and co-fermentation (SHCF) conditions to evaluate the efficiency of fermentation category. As fed-batch fermentation was observed to exhibit better results as compared to batch process, all the further shake flask experiments were conducted in fed-batch process both for SHCF and simultaneous saccharification and co-fermentation (SSCF) conditions. Scale-up experiments in 51 reactor for DG and HNG biomass were then conducted for biomass using fed-batch SSCF conditions.

\section{Batch fermentation using co-culture of S.cerevisiae and $P$. membranifaciens}

Control experiments for batch fermentation in shake flask conditions were conducted using SHCF strategy for DG and HNG biomass separately in 250-mL flasks containing $0.05 \mathrm{M}$ citrate buffer ( $\mathrm{pH}$ 5.0). The substrate concentration was taken $20 \mathrm{~g}$ in terms of ratio of glucose and xylose percentage) for DG (10:3) and HNG (6.5:2). as per the optimized conditions of single culture. Saccharification was conducted using Palkonal MBW biomass prior to fermentation. After hydrolysis condition III of co-culture fermentation of pure sugars was imitated for co-culture fermentation of both the Pennisetum sp.

\section{Fed-batch fermentation using SHCF process for ethanol production from different substrate concentrations of DG and HNG biomass}

The fed-batch fermentations for different substrate concentrations [20, 40, 60 and 80 (g)] of DG and HNG biomass were conducted separately in shake flask conditions. The fed-batch SHCF experiments for separately saccharified (Palkonal MBW and IC+XyI) DG and HNG biomass were conducted in the same procedure as mentioned in the above section. The initial and final glucose and xylose concentrations were measured in $\mathrm{g}$ for all the substrate concentrations of DG and HNG. The final ethanol concentration was measured in terms of $\mathrm{g} / \mathrm{L}$.

\section{Fed-batch fermentation using SSCF process for ethanol production from different substrate concentrations of DG and HNG biomass}

All the feed-batch SSCF experiments were started after an initial batch system ( $20 \%$ of feed with the total enzyme for the experiment) for $24 \mathrm{~h}$ in order to maintain the high temperature $\left(50{ }^{\circ} \mathrm{C}\right)$ that is required for the optimal activity of enzymes. The total enzyme concentration for Palkonal MBW $(200 \mu \mathrm{l} / \mathrm{g}$ for DG and 
$250 \mu \mathrm{l} / \mathrm{g}$ for HNG) and IC+Xyl (2.5 mL: $200 \mu \mathrm{l} / \mathrm{g}$ for DG and $2 \mathrm{~mL}: 200 \mu \mathrm{l} / \mathrm{g}$ for HNG) was given with the initial feed. After $24 \mathrm{~h}$ the temperature was lowered to $35^{\circ} \mathrm{C}$ (temperature was compromised both for saccharifying enzymes and microorganisms) and condition III of co-culture fermentation of pure sugars was imitated by using S.cerevisiae and P.membranifaciens for both the Pennisetum sp.

\section{Fed-batch fermentation using SSCF process for ethanol production from DG and HNG biomass in bioreactor}

In the reactor scale fed-batch fermentation of DG and HNG biomass was conducted for a working weight of $270 \mathrm{~g}$ using SSCF process. The feed strategy was maintained as that of the shake flask condition (30 $\%$ of the feed in batch fermentation) in which all the enzymes were added at the beginning of the fermentation process. The concentration of $250 \mu \mathrm{l} / \mathrm{g}$ and $200 \mu \mathrm{l} / \mathrm{g}$ (DG and HNG respectively) of biomass [cellulase activity of 12000 Maps cellulase unit (MCU) $/ \mathrm{mL}$ and hemicellulase activity of $5000 \mathrm{MCU} / \mathrm{mL}$ ) was kept for Palkonal MBW while for the second set of enzyme IC+Xyl the concentration was kept in a ratio of $2.5 \mathrm{~mL}: 200 \mu \mathrm{l} / \mathrm{g}$ of DG and $1.5 \mathrm{~mL}: 200 \mu \mathrm{l} / \mathrm{g}$ of HNG. The total enzyme activity of the IC was 1.35 $\mathrm{U} / \mathrm{mL}$ and $8450 \mathrm{U} / \mathrm{ml}$ for commercial xylanase enzyme. Subsequently, fed-batch fermentation was followed for $8 \mathrm{~h}$ with simultaneous addition of S.cerevisiae. After $48 \mathrm{~h}$ the substrate was centrifuged and to that $P$. membranifaciens was added. Cell loading was kept at $0.02 \mathrm{~g}$ cell/ $\mathrm{g}$ of biomass for $S$.cerevisiae and $0.01 \mathrm{~g}$ cell $/ \mathrm{g}$ of biomass for P. membranifaciens.

\section{Life cycle analysis}

Life cycle analysis for dennanath and hybrid napier grass verities were conducted using GaBi software from Think step. This analysis uses the ReCiPe method which is an end-point calculation method.

\section{Analysis of sugars and ethanol}

Analysis of glucose was conducted using DNS reagent method while analysis of xylose was conducted using bial's reagent method (Baldwin et al. 1955). Ethanol was analysed using Clarus-680 gas chromatography which was operated at an initial oven temperature of $50^{\circ} \mathrm{C}$ for $5 \mathrm{~min}$, followed by 120 ${ }^{\circ} \mathrm{C}$ for $5 \mathrm{~min}$ with a ramp rate of $15^{\circ} \mathrm{C}$ per min. The flow rate of the carrier gas was maintained at $2 \mathrm{ml} / \mathrm{min}$ and 2-propanol was used as the internal standard. All samples were appropriately diluted and filtered through a $0.2 \mu \mathrm{m}$ filter before each chromatographic analysis.

\section{Structural analysis using NMR spectroscopy}

NMR samples were prepared with ground biomass packed into a 4-mm cylindrical Zirconia MAS rotor. Solid-state NMR measurements were carried out on a Bruker DSX 300 High Resolution Multinuclear FTNMR Spectrometer. The spinning speeds were taken at different frequencies.

\section{List Of Abbreviations}


UA-NaOH: Ultrasonication assisted $\mathrm{NaOH}$; SSCF: Simultaneous saccharification and co-fermentation; SHCF: Separate hydrolysis and co-fermentation; DG: Denannath grass; HNG: Hybrid napier grass; LCA: Life cycle Analysis; NMR: Nuclear magnetic resonance spectroscopy; MCU: Maps cellulase unit; IC: Isolated cellulase; Xyl: Commercial xylanase; TRS: Total reducing sugar

\section{Declarations}

Ethics approval and consent to participate: Not applicable

Consent for publication: Not applicable

Availability of data and materials: Available

Competing interests: The authors declare that they have no competing interests

Funding: The present research work did not receive any funding.

Authors' contributions: SM participated in the design of the experiments, performed the experiments and contributed to manuscript writing. BCB participated in the design of the experiments and manuscript writing. ANA and HT supervised the research. All authors contributed to scientifc discussion. All authors read and approved the final manuscript.

Acknowledgements: The authors acknowledged the support of the staff and authorities of CET, Bhubaneswar to conduct the research work

\section{References}

1. Abbi M, Kuhad RC, Singh A (1996) Fermentation of xylose and rice straw hydrolysate to ethanol by Candida shehatae NCL-3501. J Ind Microbiol 17:20-23

2. Ajit A, Sulaimana AZ, Chisti Y (2017) Production of bioethanol by Zymomonas mobilis in highgravity extractive fermentations. Food Bioprod Proc 102:123-135

3. Almeida JRM, Modig T, Petersson A, Hägerdal BH, Lidén G, Grauslund MFG (2007) Increased tolerance and conversion of inhibitors in lignocellulosic hydrolysates by Saccharomyces cerevisiae. J Chem Technol Biotechnol 82:340-349

4. Amillastre E, Aceves-Lara CA, Uribelarrea JL, Alfenore S. Guillouete SE (2012) Dynamic model of temperature impact on cell viability and major product formation during fed-batch and continuous ethanolic fermentation in Saccharomyces cerevisiae. Biores Technol 117:242-250.

5. Bader J, Mast-Gerlach E, Popović MK, Bajpai R, Stahl U (2010) Relevance of microbial co-culture fermentations in biotechnology. J Appl Microbiol 109:371-87

6. Baldwin E, Bell DJ (1955) Cole's Practical Physiological Chemistry, published by Heffer, Cambridge, 189. 
7. Beck MJ, Johnson RD, Baker CS (1990) Ethanol production from glucose/xylose mixes by incorporating microbes in selected fermentation schemes. Appl Biochem Biotechnol 24-25:415424.

8. Boles E, Hollenberg CP (1997) The molecular genetics of hexose transport in yeasts. FEMS Microbiol Rev 21:85-111

9. Cardona CA, Sánchez OJ (2007) Fuel ethanol production: process design trends and integration opportunities. Biores Technol 98:2415-57

10. Cardona CA Sánchez OJ (2007) Fuel ethanol production: process design trends and integration opportunities. Biores Technol 98:2415-57

11. Chen $Y$ (2011) Development and application of co-culture for ethanol production by co-fermentation of glucose and xylose: a systematic review. J Ind Microbiol Biotechnol 38:581-97

12. Freitas HFS de, Olivo J, Andrade CMG (2017) Optimization of Bioethanol In Silico Production Process in a Fed-Batch Bioreactor Using Non-Linear Model Predictive Control and Evolutionary Computation Techniques. Energies 10:1763

13. Gao Y, Xu J, Yuan Z, Zhang Y, Liang C, Liu Y (2014) Ethanol Production from High Solids Loading of Alkali-Pretreated Sugarcane Bagasse with an SSF Process. Biores 9:3466-3479

14. Grootjen DRJ, Meijlink LHHM, Lans R, Luyben AM (1991) Co-fermentation of glucose and xylose with immobilized Pichia stipitis and Saccharomyces cerevisiae. Enz Microb Technol 12:860-864

15. Grootjen DRJ, Meijlink LHHM, Lans R, Luyben AM (1991) Cofermentation of glucose and xylose with immobilized Pichia stipitis and Saccharomyces cerevisiae. Enz Microb Technol 13:530-536

16. Gu H, Zhang J, Bao J (2015) High tolerance and physiological mechanism of Zymomonas mobilis to phenolic inhibitors in ethanol fermentation of corncob residue. Biotechnol Bioengineer 112:1770-82

17. Huang CF, Lin TH, Guo GL, Hwang WS (2009) Enhanced ethanol production by fermentation of rice straw hydrolysate without detoxification using a newly adapted strain of Pichia stipitis. Biores Technol 100:3914-3920

18. Kalyani, DC, Zamanzadeh M, Muller G, Horn SJ (2017) Biofuel production from birch wood by combining high solid loading simultaneous saccharification and fermentation and anaerobic digestion. Appl Energy 193:210-219

19. Koppram R, Nielsen F, Albers E, Lambert A, Wännström S, Welin L, Zacchi G, Olsson L (2013) Simultaneous saccharification and co-fermentation for bioethanol production using corncobs at lab, PDU and demo scales. Biotechnol Biofuel 6:2 https://doi.org/10.1186/1754-6834-6-2

20. Laplacea JM, Delgenesa JP, Molettaa R, Navarrob JM (1993) Ethanol production from glucose and xylose by separated and co-culture processes using high cell density systems. Proc Biochem 28:519525

21. Lee SE, Kim YO, Choi WY, Kang DH, Lee HY, Jung KH (2013) Two-Step Process Using Immobilized Saccharomyces cerevisiae and Pichia stipitis for Ethanol Production from Ulva pertusa Kjellman Hydrolysate. J Microbiol Biotechnol 23:1434-1444 
22. Miller GL (1959) Use of Dinitrosalicylic Acid Reagent for Determination of Reducing Sugar. Ann Chem 31:426-428

23. Mohapatra S, Mishra C, Behera SS, Thatoi H (2017) Application of pretreatment, fermentation and molecular techniques for enhancing bioethanol production from grass biomass - A review. Renew Sustain Energy Rev 78:1007-1032

24. Mohapatra S, Padhy S, Mohapatra PKD, Thatoi H (2018) Enhanced reducing sugar production by saccharification of lignocellulosic biomass, Pennisetum species through cellulase from a newly isolated Aspergillus fumigatus. Biores Technol 253: 262-272

25. Newcomb LL, Diderich JA, Slattery MG, Heideman W (2003) Glucose Regulation of Saccharomyces cerevisiae Cell Cycle Genes. Eukaryot Cell 2:143-149

26. Nguyen TY, Cai CM, Kumar R, Wyman CE (2017) Overcoming factors limiting high-solids fermentation of lignocellulosic biomass to ethanol. Proceed Nat Acad Sci 114 (44) 11673-11678

27. Nielsen SF, Jørgensen U, Hjorth M, Felby C, Gislum R (2017) Comparing methods for measuring the digestibility of miscanthus in bioethanol or biogas processing. Glob change biol Bioenergy 9:168175.

28. Nielsen SF, Jørgensen U, Hjorth M, Felby C, Gislum R (2017) Comparing methods for measuring the digestibility of miscanthus in bioethanol or biogas processing. Global change biology Bioenergy. 9:168-175.

29. Öhgren K, Bengtsson O, Gorwa-Grauslund MF, Galbe M, Hahn-Hägerdal B, Zacchi G (2006) Simultaneous saccharification and co-fermentation of glucose and xylose in steam-pretreated corn stover at high fiber content with Saccharomyces cerevisiae TMB3400. J Biotechnol 26:488-498

30. Olofsson K, Palmqvist B, Lidén G (2010) Improving simultaneous saccharification and cofermentation of pretreated wheat straw using both enzyme and substrate feeding. Biotechnol Biofuel 3:17 https://doi.org/10.1186/1754-6834-3-17

31. Paulova, L, Patakova P, Branska B, Rychtera M and Melzoch K (2015) Lignocellulosic ethanol: Technology design and its impact on process efficiency. Biotechnology Advances. 33:1091-107

32. Romero AM, Mateo JJ, Maicas S (2012) Characterization of an ethanol-tolerant 1,4- $\beta$-xylosidase produced by Pichia membranifaciens. Lett Appl Microbiol 55:354-361

33. Salvadó Z, Arroyo-López FN, Guillamón JM, Salazar G, Querol A Barrio E (2011) Temperature adaptation markedly determines evolution within the genus Saccharomyces. Appl Environ Microbiol 77:2292-2302

34. Shi J, Zhang M, Zhang L, Wang P, Jiang L, Deng H (2014) Xylose-fermenting Pichia stipitis by genome shuffling for improved ethanol production. Microbiol Biotechnol 7:90-99

35. Singh N, Mathur AS, Tuli DK, Gupta RPBarrow, CJ, Puri M (2017) Cellulosic ethanol production via consolidated bioprocessing by a novel thermophilic anaerobic bacterium isolated from a Himalayan hot spring. Biotechnol Biofuel 10:73 https://doi.org/10.1186/s13068-017-0756-6

36. Singla A, Shashi P, Sunder D, Sneh G, Kirti S, Seigo A, Kazuyuki I (2012) Bioethanol production from xylose: Problems and possibilities. J Biofuel 3:1-17 
37. Watkins D, Nuruddin M, Hosur M, Tcherbi-Narteh A, Jeelani S (2015) Extraction and characterization of lignin from different biomass resources. J Mat Res Technol 4:26-32

38. Westman JO, Wang R, Novy V, Franzén CJ (2017) Sustaining fermentation in high-gravity ethanol production by feeding yeast to a temperature-profiled multifeed simultaneous saccharification and co-fermentation of wheat straw. Biotechnol Biofuel 10:213. https://doi.org/10.1186/s13068-0170893-y

39. Xiros C, Olsson L (2014) Comparison of strategies to overcome the inhibitory effects in high-gravity fermentation of lignocellulosic hydrolysates. Biomass Bioenergy 65:79-90

40. Zhang M, Wang F, Su R, Qi W, He Z (2010) Ethanol production from high dry matter corncob using fed-batch simultaneous saccharification and fermentation after combined pretreatment. Biores Technol 101:4959-64

\section{Figures}
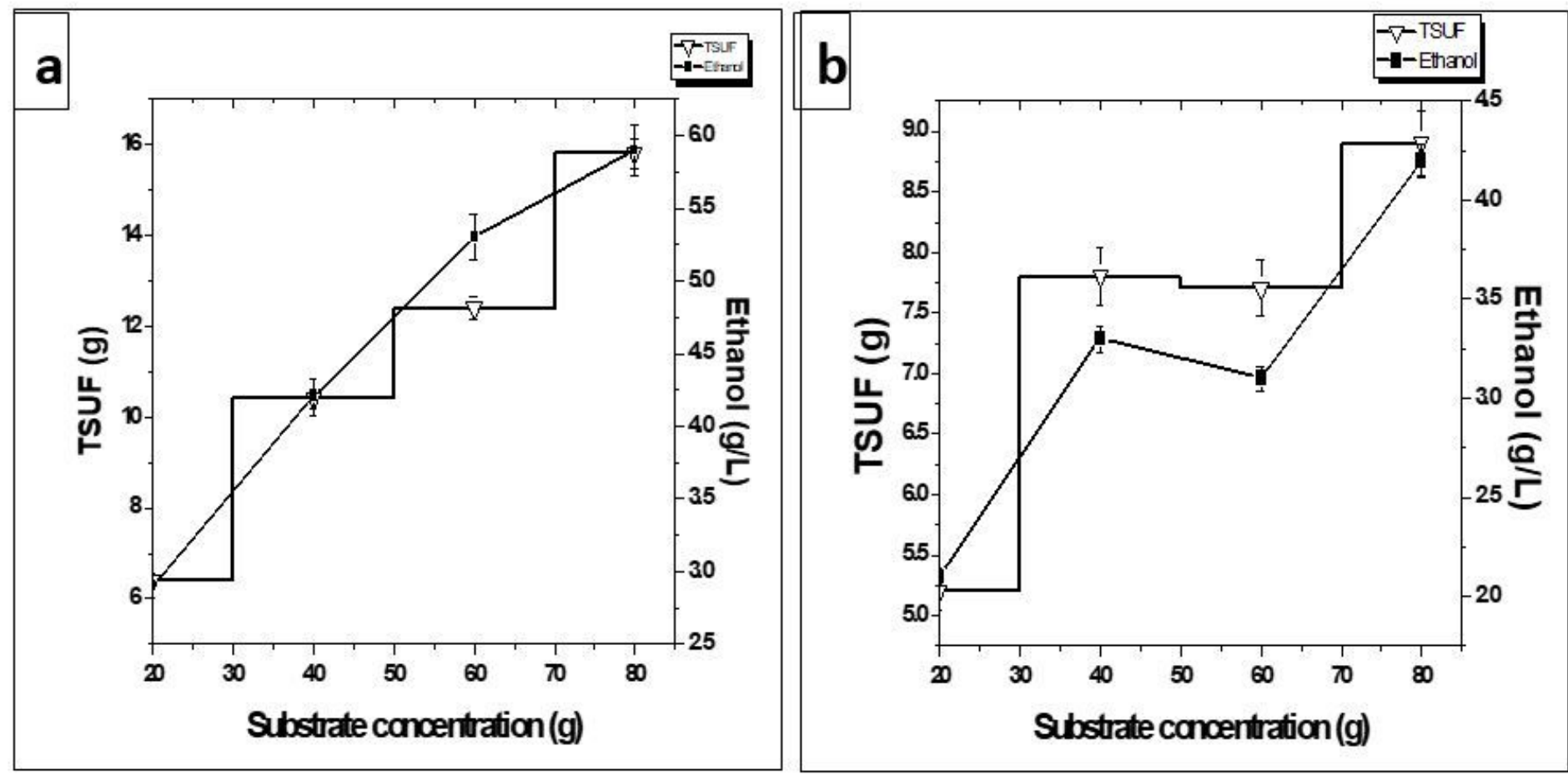

Figure 1

I. Fed-batch SHCF of UA-NaOH pretreated DG (A) and HNG (B) using Palkonal MBW. TSUF - Total reducing sugar utilized during fermentation. 

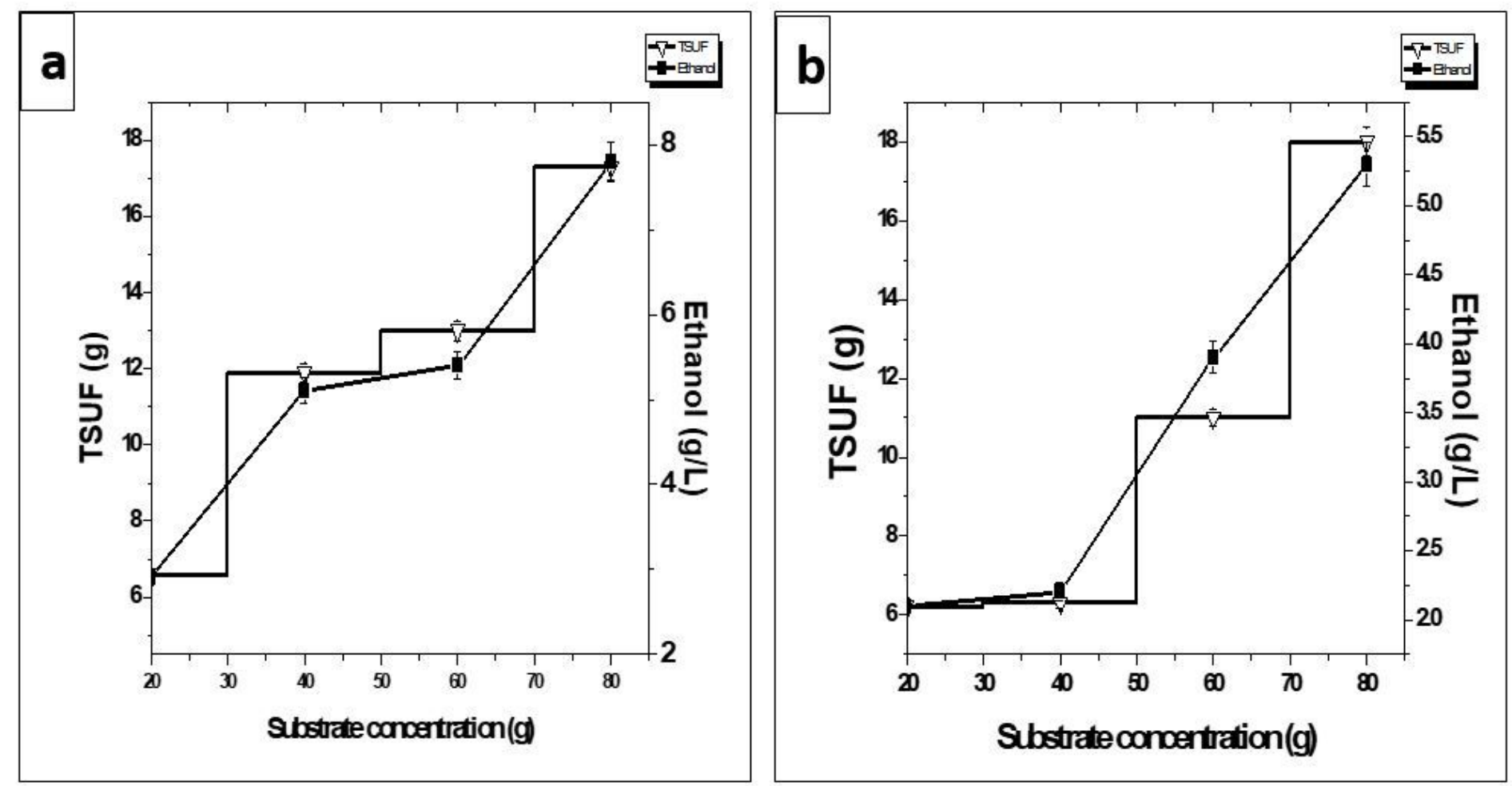

Figure 2

II. Fed-batch SHCF of UA-NaOH pretreated DG (A) and HNG (B) using IE+Xyl. TSUF - Total reducing sugar utilized during fermentation.
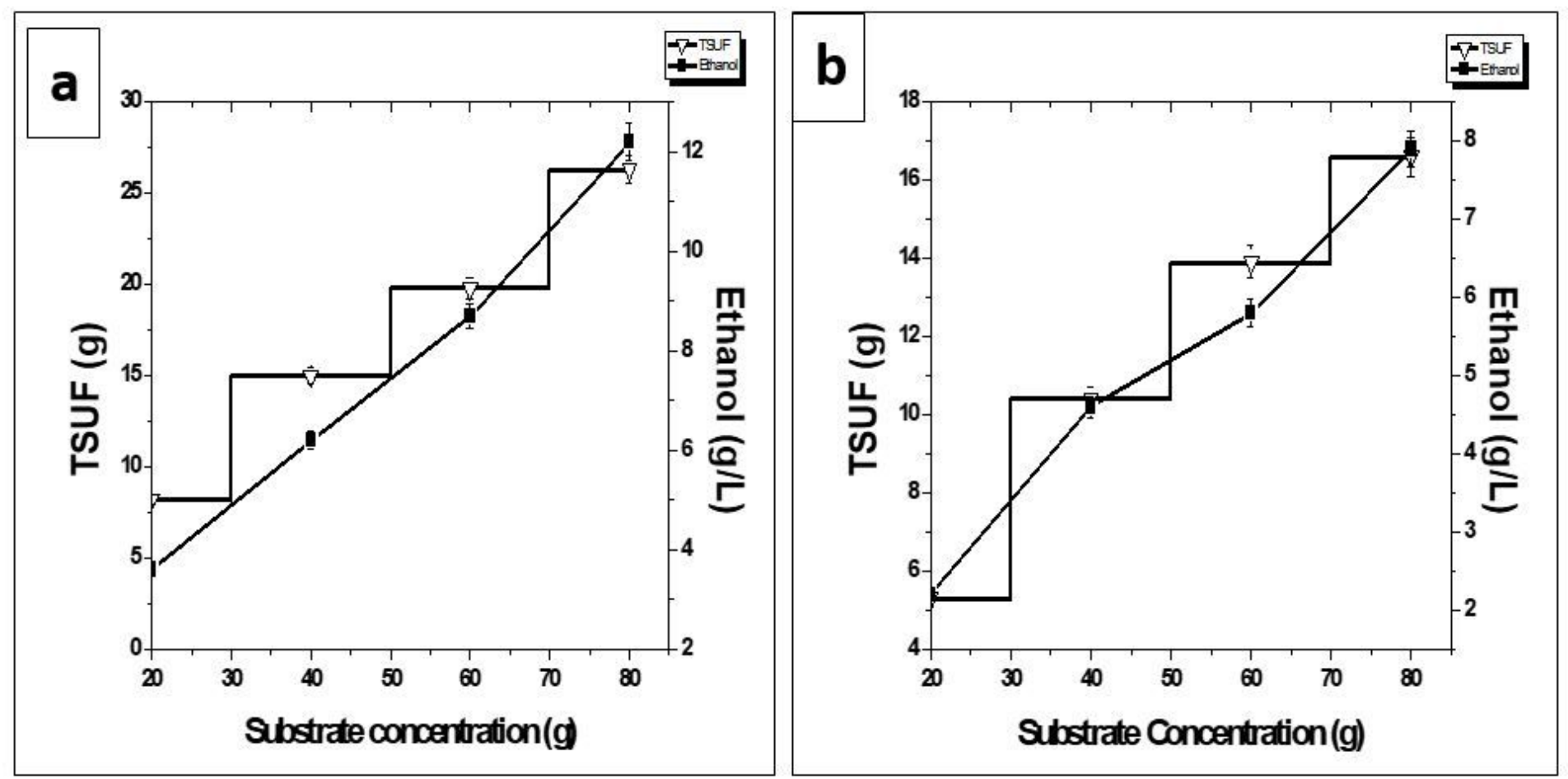

Figure 3 
I. Fed-batch SSCF of UA-NaOH pretreated DG (A) and HNG (B) using Palkonal MBW. TSUF - Total reducing sugar utilized during fermentation.
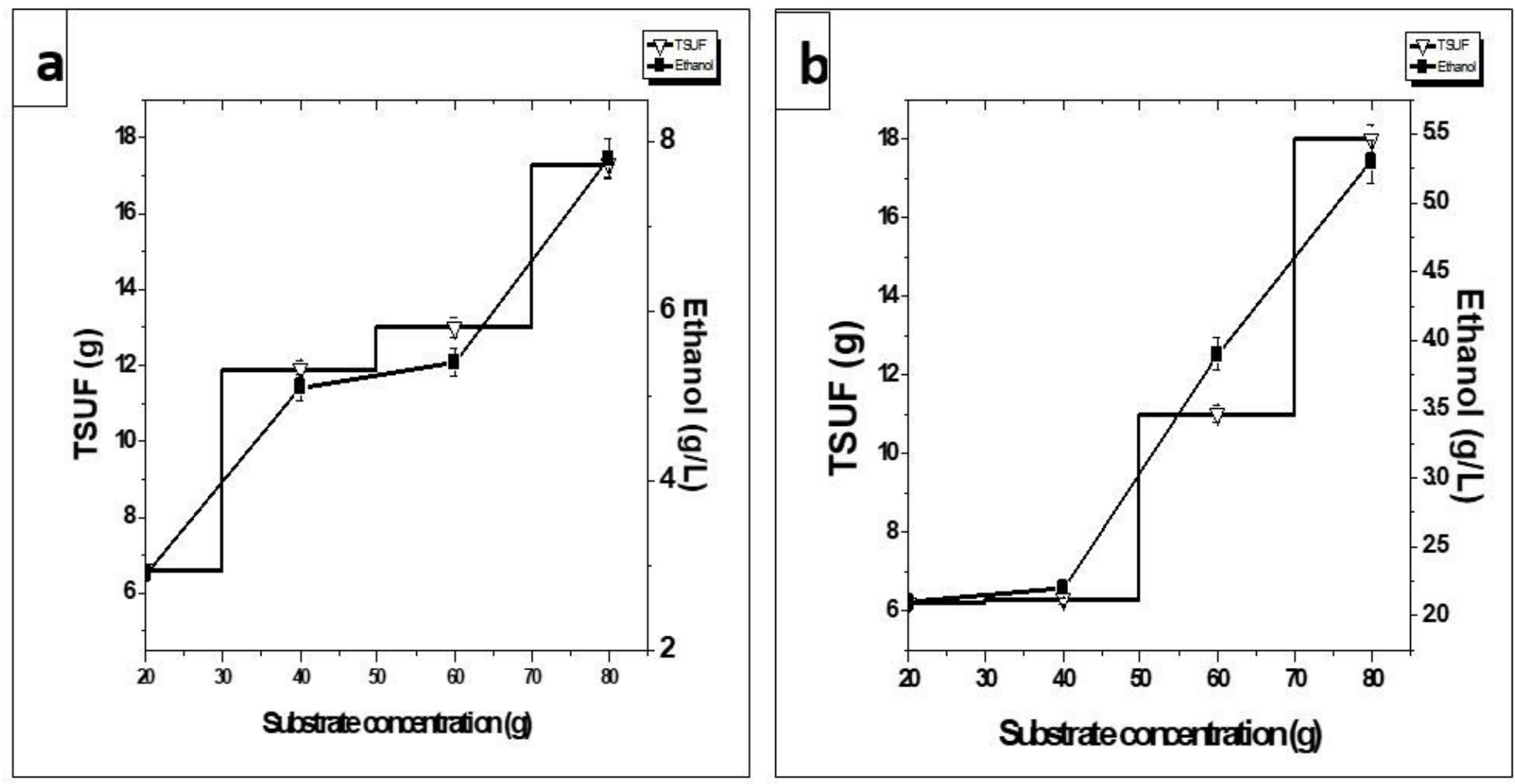

Figure 4

II. Fed-batch SsCF of UA-NaOH pretreated DG (A) and HNG (B) using IE+Xyl. TSUF - Total reducing sugar utilized during fermentation 


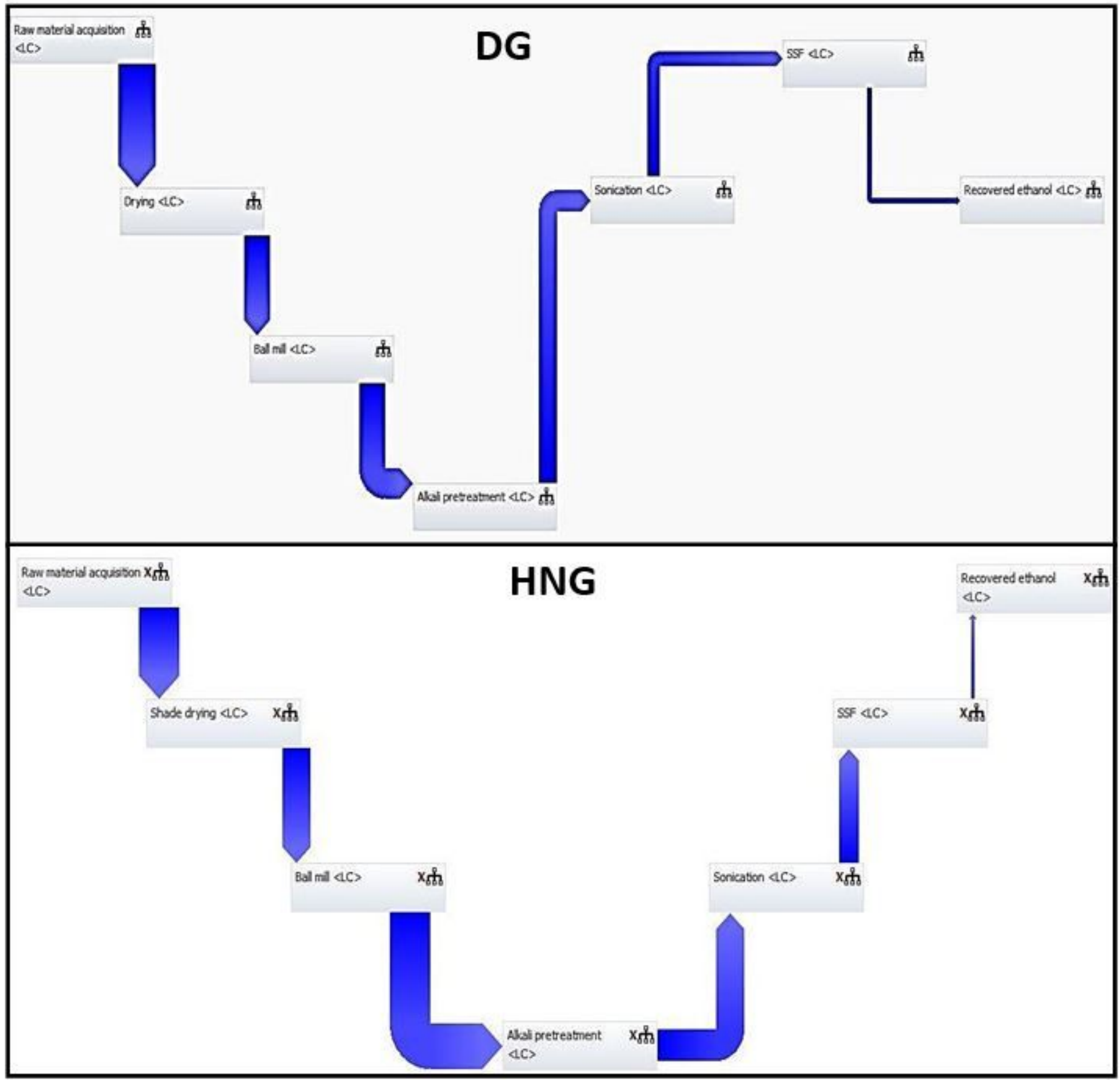

Figure 5

I. Life cycle flow diagram for the production of ethanol from DG and HNG. 

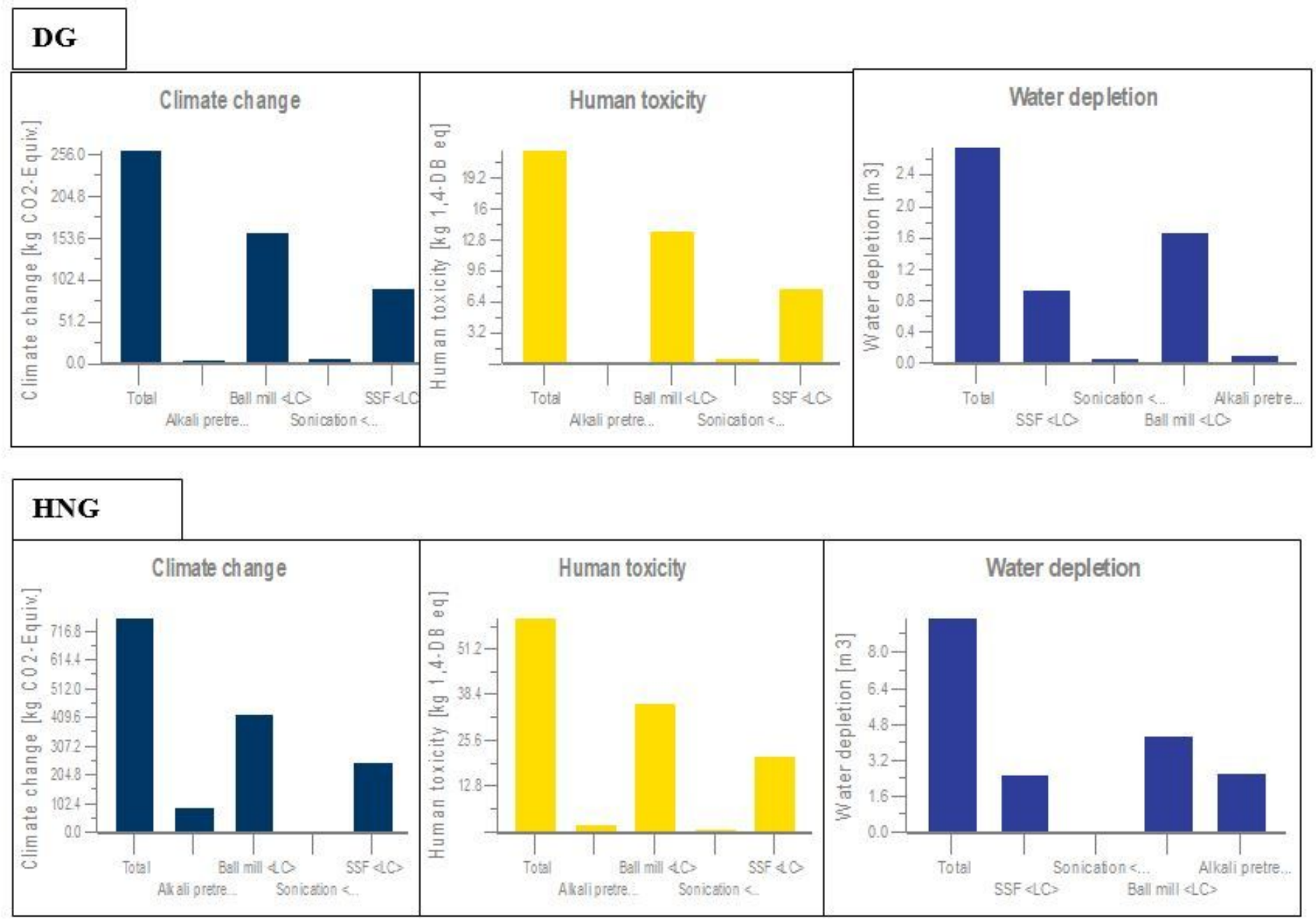

Figure 6

II. Carbon dioxide emission, human toxicity and water depletion footprints for ethanol production from DG and HNG

\section{Supplementary Files}

This is a list of supplementary files associated with this preprint. Click to download.

- Supplementary.docx

- Graphicalabstract.jpg 